\title{
Development of a Nuclear Engineering Program at Prairie View A\&M University, a Historically Black University (HBCU)
}

\author{
S. Aghara, ${ }^{\mathrm{a}^{*}}$ I. Osborne-Lee $^{\mathrm{a}}$ and Mehran Viseh ${ }^{\mathrm{b},}$ Richard Wilkins $^{\mathrm{c}}$ \\ a Department of Chemical Engineering, Prairie View A\&M University, \\ Prairie View, TX/ \\ b Department of Computer Engineering, Prairie View A\&M University, \\ Prairie View, TX \\ ${ }^{c}$ Department of Electrical Engineering, Prairie View A\&M University, \\ Prairie View, TX
}

\begin{abstract}
Prairie View A\&M University (PVAMU), one of the nation's leading Historically Black Universities (HBCUs), in 2002 through the DOE Minority/Majority University Partnership Program (MMUPP) established a nuclear engineering program in its chemical engineering department. This paper will discuss the courses and the curriculum being developed at PVAMU as part of its strategy to help supply nuclear engineering graduates for the next generation. Since its early days until the early 1980s, there was a tremendous interest in nuclear engineering and it was easy to attract and retain the best young talent to this field. However, with a combination of nuclear accidents in the power sector and the end of cold war, the public perception and the political significance of the nuclear industry has been on a decline. This has lead to a shrinking supply of new nuclear engineering graduates with competence in design, modeling and operation of nuclear power reactors and the peripheral industry. A 2002 American Nuclear Society (ANS) report states that the supply of graduates with nuclear engineering background has depleted significantly over the years leading to a serious personnel shortage in all applied fields of nuclear engineering ${ }^{1}$.

To address this developing concern many national organizations have initiated programs to support and develop nuclear engineering curriculum that will educate students in the field of nuclear science. PVAMU's nuclear engineering program is geared towards educating and contributing engineering students with nuclear background. These students will be educated so that they can either find placements in the nuclear industry or pursue advance nuclear engineering degrees at other institutions. The Journal of Blacks in Higher Education (JBHE) reports that the overall percent of graduating Blacks in science and engineering is substantially lower then in other fields ${ }^{2}$. Enrollments at traditional nuclear programs have declined over the years and hence it should be no surprise that the challenge to encourage and involve students in nuclear program is also felt at PVAMU. The paper will discuss the course curriculum and the overall approach to encourage student enrollment in nuclear classes.
\end{abstract}

"Proceedings of the 2005 American Society for Engineering Education Annual Conference Copyright (c) 2005, American Society for Engineering Education” 
Introduction

The nuclear engineering program at PVAMU was established through the DOE Office of Nuclear Energy, Science and Technology Nuclear Engineering University Partnership program. The program involves three universities; Texas A\&M University (TAMU), Texas A\&M University Kingsville (TAMUK), a Hispanic Serving Institution, Prairie View A\&M University (PVAMU), a Historically Black University, all three being part of the Texas A\&M system. TAMU, the lead university in the partnership, offers undergraduate as well as graduate degrees in nuclear engineering and is one of the largest nuclear engineering departments in U.S. TAMUhas the ability to offer courses to both TAMUK and PVAMU through the Trans-Texas Videoconference Network (TTVN) system. This is expected to benefit the PVAMU program as the requirement to develop courses is reduced and students can enroll in all the courses offered by the nuclear engineering department at TAMU through TTVN. Being a new program, the challenge lays in recruitment of students into the nuclear engineering classes. There are a couple of possible causes for this. First, lack of African Americans in nuclear related professions nationally contributes to absence of role models and community of peers. Secondly, there has been a lack of physical presence of a faculty member with a nuclear engineering background at PVAMU campus. The recent hiring of a new faculty member with a nuclear engineering background dedicated specifically to the development of the program it is expected to boost student enrollment in courses offered at PVAMU campus and the TTVN classes. Also a national recognition by numerous DOE laboratories of the need to increase minority enrollments at such institutions is expected to influence students at the universities to consider nuclear engineering as a prospective career option.

The uniqueness of the PVAMU program comes from the way it is setup. It is based in the Department of Chemical Engineering and the NASA Center for Applied Radiation Research (CARR) is an integral part of the program. The course curriculum is desired to include specific topics covering radiation environments and radiation detection as applicable to space. The program is geared towards a non-power related nuclear engineering instruction. The program is expected to evolve in the areas of radiation biology, health physics, radiation environment characterization and radiochemistry. A course titled "Introduction to Nuclear Engineering I" was developed and taught at PVAMU for the Fall 2004 semester, for the spring semester same course is offered again along with a second course titled "Introduction to Nuclear Engineering II". The syllabus of these courses will be discussed along with the future plans of the courses being planned at PVAMU. This paper will not discuss the development of the Texas partnership program or the sharing of the TTVN courses.

"Proceedings of the 2005 American Society for Engineering Education Annual Conference Copyright (C) 2005, American Society for Engineering Education” 
In the fall of 2004 a special topics course titled "CHEG-4103.002: Introduction to Nuclear Engineering I” was offered as a 3 credit hour technical elective in the college of engineering at PVAMU. Being a new topic it was limited to engineering seniors as it was expected to serve as a technical elective to students in the college of engineering. All engineering students are required to take two technical electives of their choice. The Catalog details of the course are given in Table I.

\section{Table 1 :- 2003-04 Chemical Engineering Course Catalog Data ${ }^{3}$}

\begin{tabular}{|l|l|}
\hline Course number and Title & CHEG 4103.002, Special Topic in Chemical Engineering. \\
\hline Course Credit & Credit 3 semester hours (3 lecture -0 laboratory). \\
\hline Course Description & $\begin{array}{l}\text { This course will explore the fundamental principles of the } \\
\text { interaction of nuclear and atomic radiation with matter. } \\
\text { Being taught for the first time the course material will be } \\
\text { adjusted based on the level of students in the class as } \\
\text { determined by department faculty. Student will be } \\
\text { introduced to basics of nuclear engineering and it's } \\
\text { application. }\end{array}$ \\
\hline Prerequisite & College of Engineering Seniors only \\
\hline
\end{tabular}

There are quite a few choices available for textbooks to supplement the class notes to teach the topics covered in the class. Among all the available choices, Mayo was chosen as the required textbook for the class and Lamarsh was chose as a recommended reference. Mayo covers the nuclear physics part in a little more detail, which was felt to be necessary for the students to appreciate and understand the advanced nuclear engineering concepts. The chart of nuclides was also included as a reference text. Students were expected to use the chart of nuclides in exams as they were taught with a lecture dedicated to understanding and interpreting the information given therein. The class notes were all developed in Power Point ${ }^{\circledR 3}$ format and were distributed to the students as additional reference material. The entire course is developed in an electronic format so that in near future it can be taught as a web based class offered to other universities within the partnership program.

Table 2:- Text and Reference for CHEG 4103.002

\begin{tabular}{|l|l|}
\hline Textbook & $\begin{array}{l}\text { Robert M. Mayo “Introduction to Nuclear Concepts for } \\
\text { Engineers, ” ISBN 0-8944-4-454-0, American Nuclear } \\
\text { Society, La Grange Park, Illinois (1998). }\end{array}$ \\
\hline References & $\begin{array}{l}\text { J.R. Lamarsh and A.J. Baratta, "Introduction to Nuclear } \\
\text { Engineering,” Third Edition, Prentice Hall, Upper Saddle } \\
\text { River, New Jersey (2001). } \\
\text { Knolls Atomic Power Laboratory, "The Chart of the } \\
\text { Nuclides" (1996). }\end{array}$ \\
\hline
\end{tabular}

"Proceedings of the 2005 American Society for Engineering Education Annual Conference Copyright @ 2005, American Society for Engineering Education” 
The first three lectures focused on the brief review of the history of nuclear physics and nuclear engineering, followed by a detailed description of the scope of nuclear engineering and its application. A great deal of information was given on nonpower applications in the field of nuclear engineering. It was felt necessary to give the students a full breadth of the scope of nuclear engineering to get them interested and involved in the concepts presented later in the course. Students were also asked to pick one of the many topics discussed in class to be part of their project topic. The project required each student to do a short Power Point ${ }^{\circledR}$ presentation and write a brief 5-page report to be submitted at the end of the semester. The list of lecture topics is given in Table 3.

\section{Table 3:- Lecture Distribution for CHEG 4103.002}

\begin{tabular}{|l|l|}
\hline Lecture 1 & Syllabus Day \& Introduction \\
\hline Lecture 2 & Historical Journey \\
\hline Lecture 3 & Nuclear Particles and Nuclear Notations \\
\hline Lecture 4 & The Atomic Nucleus I \\
\hline Lecture 5 & Nuclear Size and Its Units \\
\hline Lecture 6 & Introduction to Nuclear Models \\
\hline Lecture 7 & Nuclear Reactions \\
\hline Lecture 8 & Nuclear Stability and Radioactivity \\
\hline Lecture 9 & Binding Energy \\
\hline Lecture 10 & Conservation Laws: Mass/Energy Relationship \\
\hline Lecture 11 1 Threshold Energy for a Nuclear Reactions \\
\hline Lecture 12 & Modes of Radioactive Decay I \\
\hline Lecture 13 & Modes of Radioactive Decay II \\
\hline Lecture 14 & Radioactive Decay Laws \& Kinetics \\
\hline Lecture 15 & Production and Decay of Radioactivity \\
\hline Lecture 16 & Number Density Calculations \\
\hline Lecture 17 & Radiation Interactions \\
\hline Lecture 18 & Neutron Interactions \\
\hline Lecture 19 & Fission and Fusion Introduction \\
\hline Lecture 20 & Buildup and Decay Calculations \\
\hline
\end{tabular}

The lectures were adjusted according to the students' rate of progress. The concepts covered towards the end of the course specifically in nuclear interactions and induced radioactivity required additional time and extra assignments. As designed, the "Introduction to Nuclear Engineering II" will cover these topics in more detail before the students are taught the solution to the diffusion equation and its solution for specific reactor geometries. Overall, the response to the course was better then expected with many students expressing interest in the follow-on course. Additionally many new students having learned from your fellow students have inquired about enrollment in the same course offered in Fall 2005. Given this response, plans are to offer both courses for the spring semester.

"Proceedings of the 2005 American Society for Engineering Education Annual Conference Copyright (c) 2005, American Society for Engineering Education” 


\section{Distance Learning and Web Based Classroom}

The courses developed for the nuclear engineering program are being developed as web based courses. The course held in Fall 2004 was taught in a multimedia classroom even though it did not have any off campus students. The intention is to use the modern teaching techniques with visual illustration as adequate to increase student participation and involvement in mathematically intensive engineering topics. The classroom used during the teaching of the course had the following technical specifications. Figure 1, shows a live shot of class being taught in the multimedia classroom.

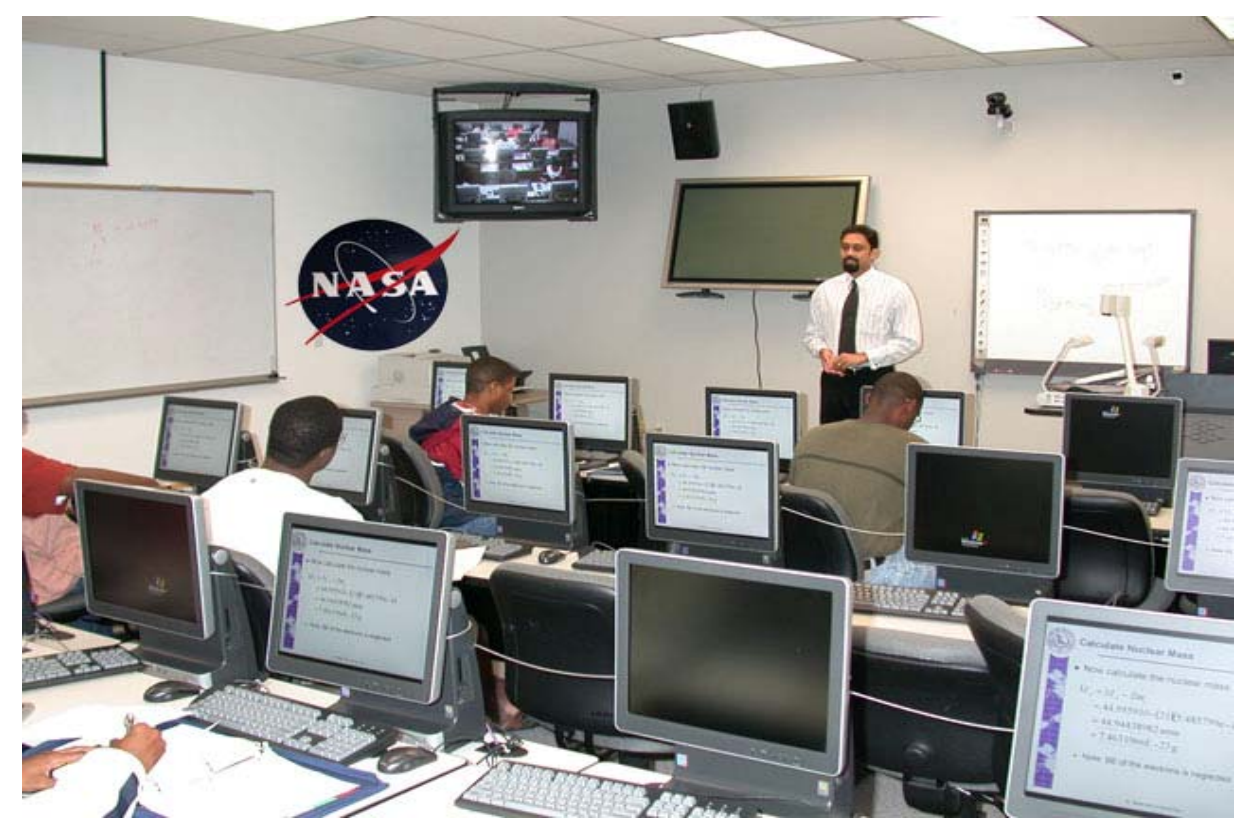

Figure 1: Picture showing a snapshot of the class taught in multimedia classroom.

\section{Features}

- Professional BNC video connectors that improve video quality, secure video connections.

- High-performance audio, video, and data including support for up to four simultaneous monitors with an additional high-resolution projector.

- Extended API commands for AMX/Crestron control panels, the VS4000 (rackmountable video conferencing) [ref] is the integrator's choice for custom integrations and vertical applications. 


\section{VS4000 Highlights}

- Intelligent video algorithm selection for premium video quality from low bandwidths (ITU-T H.264) to high (ITU 60 fields)

- Embedded multipoint support up to two Mbps connects up to four sites over Internet Protocol (IP), Integrated Services Digital Network (ISDN) or mixed networks, plus one international analog phone line; cascading up to 14 sites (10 video plus 4 audio)

- Add simultaneous PC audio and XGA content while still seeing presenter

- Embedded graphics-based Web server for diagnostics and system management via the Internet

- RS-232 control / data communications port

- Optional private network support; V.35, RS-530, RS-449, and RS-366 interfaces

- Optional National Institute of Standards and Technology (NIST)-validated, Federal Information Processing Standards Publications (FIPS)-compliant AES (Advanced Encryption Standard) security

The classroom is equipped with individual computers for each student in the class, a standard overhead projector, multi port plasma TV's and a touch sensitive white board. The layout of the classroom is show in figure 2.

\section{Video Conferencing}

- Standard IP Base

csv.pvamu.edu or 129.207.8.197

- Broadcasting up to 5 sites concurrently

- Recording Sessions on tape and digital

- Operating System - WinXP Pro ${ }^{\circledR}$

Equipment

- 24 Profile5 Gateway ${ }^{\circledR}$ Workstation $3.0 \mathrm{GHZ}$

- 1 Giga Bites (GB) Memory

- 80 GB Hard Drive

- Floppy and DVD Drive

- 19" Liquid Crystal Display (LCD)

Monitor

150 " Plasma TV

- 2 40" TV, 135 " TV

- HP LaserJet ${ }^{\circledR}$ Printer 4100n

- Overhead projector

Physical Location

- S.R. Collins Bldg. - Rm. 210

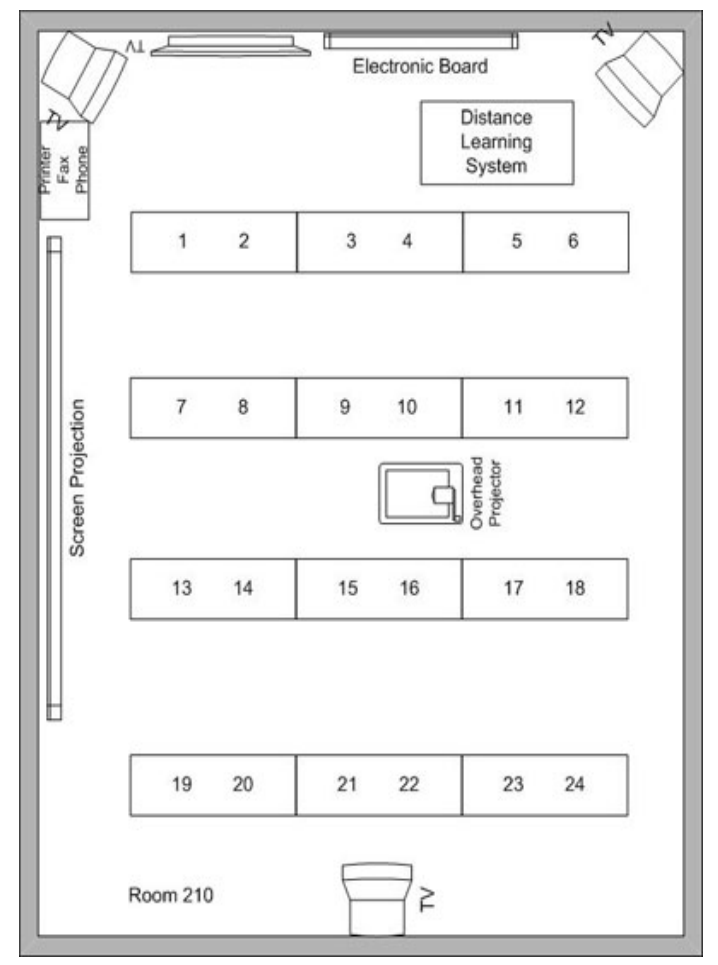

Figure 2: List of equipment and layout of the multimedia classroom. 
Future Plans

The development of the course in nuclear engineering at the PVAMU campus for the Fall 2004 semester has resulted in an encouraging interest in the nuclear engineering program at PVAMU. The student enrollment in the following two classes offered in spring of 2005 is up with students interested in taking classes offered via TTVN from TAMU. It appears that the presence of faculty at PVAMU focused in nuclear engineering has helped boost awareness among students of this field with an increasing number of students interested in enrolling in nuclear engineering classes.

For the near future a course geared towards sophomores is being envisioned that would aid in increasing student enrollment in higher-level nuclear engineering courses. Additionally it is proposed to cross-list some courses between the College of Engineering and the Department of Physics to boost student numbers in courses and enable additional courses to be offered. It seems that in the course of 2-3 semesters a set of courses will be offered as regular courses approved by the curriculum committee. At this point it seems necessary to initiate the acquisition of radiation detectors so that a radiation detection laboratory can be established that will be used for research and for teaching a laboratory class. A course of this type is being planned to be offered within a years time. Such a course would give students practical training along with theoretical knowledge preparing them with skills desired by employers in the field of nuclear engineering and for further graduate studies in nuclear engineering.

\section{Bibliography}

1. Human Capital in Nuclear Science and Technology. Position statement of the American Nuclear Society, November 2002.

2. Web link for the article in Journal of Blacks in Higher Education, http://www.jbhe.com/news_views/42_PhDs_and blacks.html

3. Fall 2004 Schedule of Classes, Prairie View A\&M University

4. Power Point is a registered trademark of the Microsoft Corporation.

5. Polycom ViewStation product line http://www.polycom.com/home/ 


\section{Biography}

Dr. Sukesh Aghara is an Assistant Professor in the Department of Chemical Engineering. He is also a member of the research faculty with the NASA Center for Applied Radiation Research. He is appointed to develop the nuclear engineering program at PVAMU. He earned his masters and Ph.D. degrees in nuclear engineering from The University of Texas at Austin. His research interests include characterization of radiation environment (neutrons and gamma) for fundamental materials research and space radiation effects in material; and radiation shielding analysis for ground based system and space radiation environment. He joined PVAMU in June 2004.

Dr. Osborne-Lee is Associate professor and Head of the chemical engineering department since 1998. He is principal investigator for the PVAMU portion of the Minority Majority University Partnership in Nuclear Engineering and Health Physics, funded by the U. S. Department of Energy. He earned the B.S., M.S., and Ph.D. degrees from The University of Texas at Austin in chemical engineering.

Mr. Mehran Viseh - is Network Administrator and Webmaster in the Department of Computer Science. He has been involved with the development of the distance learning classroom. He has been with PVAMU for last 6 years. 